\title{
Electron Transfer around a Molecular Corner
}

\author{
Hauke C. Schmidt, ${ }^{[a]}$ Christopher B. Larsen, ${ }^{\left[{ }^{[a]}\right.}$ and Oliver S. Wenger ${ }^{*[a]}$
}

\begin{abstract}
The distance dependence of electron transfer $(E T)$ is commonly investigated in linear rigid rod-like compounds, but studies of molecular wires with integrated corners imposing $90^{\circ}$ angles are very rare. By using spirobifluorene as a key bridging element and by substituting it at different positions, two isomeric series of donor-bridge-acceptor compounds with either nearly linear or angled geometries were obtained. Photoinduced ET in both series is dominated by rapid through-bond hole hopping across oligofluorenes over distances of up to $70 \AA$. Despite considerable conformational flexibility, direct through-space and through-solvent $E T$ is negligible even in the angled series. The independence of the ET rate constant on the total number of fluorene units in the angled series is attributed to a rate-limiting tunneling step through the spirobifluorene corner. This finding is relevant for multi-dimensional ET systems and grids in which individual molecular wires are interlinked at $90^{\circ}$ angles.
\end{abstract}

Photoinduced electron transfer has been widely explored in artificial and natural systems. Whilst numerous studies focused on the influence of driving-force and reorganization energy on electron transfer rates, ${ }^{[1]}$ many other investigations concentrated on their distance dependence. ${ }^{[2]}$ A key goal was often the generation of long-lived charge-separated states and the mimicry of elementary processes in natural photosynthesis. ${ }^{[3]}$ Linear rigid rod-like donor-acceptor compounds and straight molecular wires were frequently preferred, ${ }^{[4]}$ because this permits the investigation of through-bond electron transfer over well-defined donor-acceptor distances and a separation of charges over maximal distance. By contrast, rigid molecular bridges or wires containing $90^{\circ}$ angles are very uncommon. ${ }^{[5]}$ Prior investigators employed octahedral metal complexes as photosensitizers with donor and acceptor units attached to different ligands that were coordinated at ca. $90^{\circ}$ angles relative to one another, ${ }^{[6]}$ but this is conceptually much different from the situation in which a corner is integrated into the molecular wire. We hypothesized that spirobifluorene as a key bridging unit between a donor and an acceptor could provide access to linear and angled isomers of rigid rod-like donor-acceptor dyads (Scheme 1). When complemented with additional fluorene bridging units on both sides of the central spirobifluorene element, donor and acceptor branches of variable lengths should be accessible (Scheme 1). Both branches would then have a rigid rod-like structure, but depending on the substitution pattern at the spirobifluorene unit either linear or angled isomer series should be accessible. Electron delocalization across spiro-centers has been investigated in mixed-valence

[a] Dr. H. C. Schmidt, Dr. C. B. Larsen, Prof. Dr. O. S. Wenger Department of Chemistry, University of Basel St. Johanns-Ring 19, 4056 Basel (Switzerland) E-mail: oliver.wenger@unibas.ch

Supporting information for this article is given via a link at the end of the document. compounds, ${ }^{[7]}$ but we are unaware of prior studies that explored long-range electron transfer in spirobifluorene-based systems with both linear and angled geometries. This comparison should provide direct insight into the relative efficiencies of different charge transfer pathways, and this is relevant in the greater context of a future molecular electronics technology. ${ }^{[8]}$ Both linear and $\pi$-stacked oligo-fluorenes were previously identified as molecular wires that mediate long-range electron and energy transfer very efficiently. ${ }^{[9]}$ Spirobifluorene plays a key role in hole transport materials for solar cells, ${ }^{[10]}$ and it has also been explored in the context of luminescent materials. ${ }^{[1]]}$
Angled Isomers

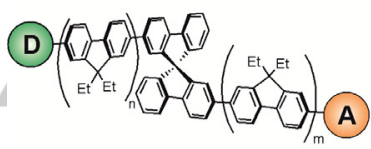

Linear Isomers

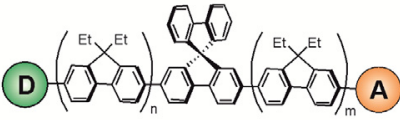

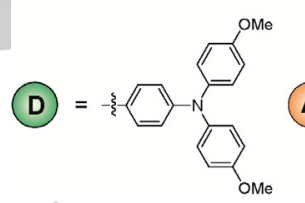

(A)

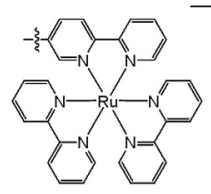

\begin{tabular}{|c|c|c|}
\hline compound & $\mathrm{n}$ & $\mathrm{m}$ \\
\hline $\mathrm{A} 1$ & 1 & 1 \\
\hline $\mathrm{A} 2$ & 2 & 2 \\
\hline $\mathrm{A} 3$ & 3 & 3 \\
\hline $\mathrm{L} 1$ & 1 & 1 \\
\hline $\mathrm{L} 2$ & 2 & 2 \\
\hline $\mathrm{C} 1$ & 0 & 2 \\
\hline
\end{tabular}

Scheme 1. Molecular dyads investigated in this work. $\mathrm{C} 1$ has the same angled structure as $\mathrm{A} 1, \mathrm{~A} 2$ and $\mathrm{A} 3$, but with different relative bridge lengths between donor and acceptor branches. The linking position of the donor and the acceptor is the same in all 6 compounds.

A triarylamine (TAA) unit and a $\left[R u(b p y)_{3}\right]^{2+}$ (bpy $=2,2^{\prime}$ bipyridine) complex $(\mathrm{Ru})$ were chosen as a donor and an acceptor, respectively, because this combination has favorable optical spectroscopic properties and there is enough drivingforce for long-range electron transfer after photoexcitation of the metal complex, at least in so-called flash-quench experiments (see below). For the linear series of dyads, we managed to synthesize compounds with either 3 or 5 fluorene units between TAA and Ru (L1, L2). For the angled series, dyads with 3, 5, and 7 fluorene units between TAA and Ru could be synthesized and explored (A1 - A3). Synthetic details and characterization data are in the Supporting Information (SI pages S2-S30).

Not too surprisingly, in vacuo Merck Molecular Force Field (MMFF) energy minimization calculations quickly dispersed the notion of the angled series having a strictly rigid rod-like rightangled structure. Instead, two low energy conformers can be readily identified: an open 'winged' conformer, and a closed conformer in which the TAA and $\left[\mathrm{Ru}(\mathrm{bpy})_{3}\right]^{2+}$ units approach one another, with $\mathrm{N}_{\mathrm{TAA}}-\mathrm{Ru}$ distances of 7.6, 8.9 and 9.0 $\AA$ for $\mathrm{A} 1, \mathrm{~A} 2$ and $\mathrm{A} 3$, respectively (SI page S40-S41). This second conformer is predicted to be lower in energy by $8 \mathrm{~kJ} \mathrm{~mol}^{-1}$ for $\mathrm{A} 1,26 \mathrm{~kJ} \mathrm{~mol}^{-}$

${ }^{1}$ for $\mathrm{A} 2$, and $27 \mathrm{~kJ} \mathrm{~mol}^{-1}$ for $\mathrm{A} 3$, compared to the open conformer (SI page S41). MMFF is a low, computationally inexpensive level 
of theory and these stabilization values are therefore likely exaggerated by the calculations. ${ }^{[12]}$ Furthermore, as the calculations are performed in vacuo, solvent stabilization effects are not taken into consideration. The key message from these calculations is that in the angled isomer series conformers with relatively short through-space but long through-bond distances can form. Electron transfer in such systems can either proceed through the long bonding system, or across the short space between donor and acceptor. ${ }^{[13]}$ In the linear series, by contrast, only the through-bond pathway is available. To further separate the role of through-bond and through-space electron transfer, an additional angled control compound, C1, was prepared, in which a close contact between the donor and acceptor cannot form (Scheme 1).

The TAA and $\left[\mathrm{Ru}(\mathrm{bpy})_{3}\right]^{2+}$ redox potentials are very similar in the 6 dyads (SI pages S32-S34), leading to essentially identical driving-forces for intramolecular electron transfer in all cases. For photoinduced electron transfer from TAA to ${ }^{3} \mathrm{MLCT}$-excited $\left[\mathrm{Ru}(\mathrm{bpy})_{3}\right]^{2+}$ the reaction free energy is relatively small $\left(\Delta \mathrm{G}_{\mathrm{ET}}{ }^{0} \approx-\right.$ $0.2 \mathrm{eV}$ ), making the observation of long-range charge transfer challenging because the rates can get slow compared to the ${ }^{3} \mathrm{MLCT}$ lifetime. However, in presence of excess methylviologen $\left(\mathrm{MV}^{2+}\right)$, the ${ }^{3} \mathrm{MLCT}$-excited complex is oxidatively quenched to yield $\left[\mathrm{Ru}(\mathrm{bpy})_{3}\right]^{3+}$ within less than $10 \mathrm{~ns}$ (SI page S35), ${ }^{[14]}$ and the $\mathrm{Ru}(\mathrm{III})$ species is then reduced by TAA with substantially greater driving-force $\left(\Delta \mathrm{G}_{\mathrm{ET}}{ }^{0} \approx-0.7 \mathrm{eV}\right)$. Bimolecular thermal reverse electron transfer from $\mathrm{MV}^{+}$to $\mathrm{TAA}^{+}$subsequently takes places on a longer timescale ( $40 \mu \mathrm{s}$, SI page S35). ${ }^{[14]}$ This socalled flash-quench technique was most useful to explore longrange electron transfer in our dyads.

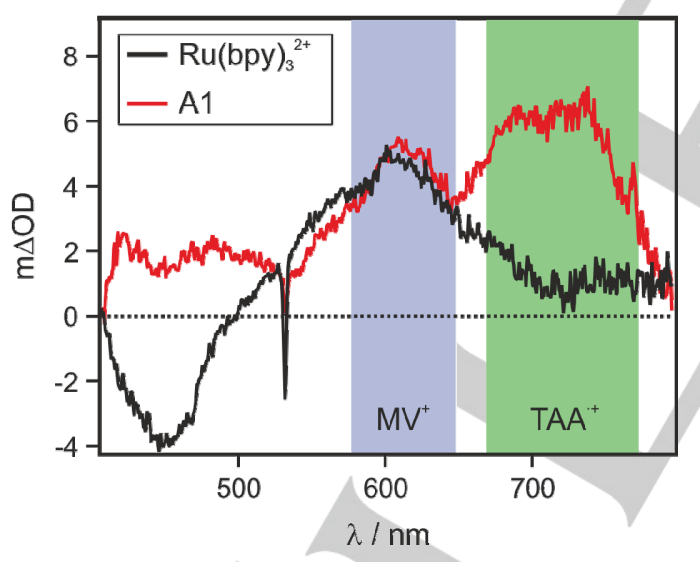

Figure 1. Transient absorption spectra obtained after excitation at $532 \mathrm{~nm}$ with laser pulses of ca. $10 \mathrm{~ns}$ duration: $15 \mu \mathrm{M}$ dyad A1 with $80 \mathrm{mM} \mathrm{MV}^{2+}$ (red trace), and $15 \mu \mathrm{M}\left[\mathrm{Ru}(\mathrm{bpy})_{3}\right]^{2+}$ with $80 \mathrm{mM} \mathrm{MV}{ }^{2+}$ (black trace) in de-aerated $\mathrm{CH}_{3} \mathrm{CN}$ at $22{ }^{\circ} \mathrm{C}$.

All dyads exhibit intense fluorene-localized $\pi-\pi^{*}$ absorption bands between 370 and $385 \mathrm{~nm}$, but at $532 \mathrm{~nm}$ photoexcitation occurs selectively into MLCT absorptions of the photosensitizer units (SI page S36). The transient absorption spectrum of $\mathrm{A} 1$ recorded in presence of $\mathrm{MV}^{2+}$ (red trace Figure 1) is typical for all 6 dyads (SI page S37). In all cases, the dyad concentration was $15 \mu \mathrm{M}$, whilst $\mathrm{MV}^{2+}$ was present at $80 \mathrm{mM}$ in de-aerated
$\mathrm{CH}_{3} \mathrm{CN}$ at room temperature. The duration of the laser pulses was ca. $10 \mathrm{~ns}$, and transient absorption spectra were recorded by time-integration over a period of 200 ns immediately after excitation. The key observation is the transient absorption band at $730 \mathrm{~nm}$, which is diagnostic for $\mathrm{TAA}^{+}$(SI page S38), ${ }^{[15]}$ in addition to a band at $605 \mathrm{~nm}$ caused by $\mathrm{MV}^{+} \cdot{ }^{[16]}$ Evidently, selective excitation of the Ru sensitizer at $532 \mathrm{~nm}$ leads to the formation of both $\mathrm{TAA}^{+}$and $\mathrm{MV}^{+}$, and this can be explained by rapid oxidative ${ }^{3} \mathrm{MLCT}$ excited-state quenching by $\mathrm{MV}^{2+}$, followed by intramolecular electron transfer from TAA to the $\left[\mathrm{Ru}(\mathrm{bpy})_{3}\right]^{3+}$ unit, as noted above. When performing the same experiment with the commercial $\left[\mathrm{Ru}(\mathrm{bpy})_{3}\right]^{2+}$ reference complex, one still observes the $\mathrm{MV}^{+}$band at $605 \mathrm{~nm}$ (black trace in Figure 1), but instead of the $\mathrm{TAA}^{+}$absorption at $730 \mathrm{~nm}$ there is now an MLCT bleach at $450 \mathrm{~nm}$ signaling the disappearance of $\left[R u(b p y)_{3}\right]^{2+}$ and the formation of $\left[\operatorname{Ru}(b p y)_{3}\right]^{3+}$, in line with expectation.

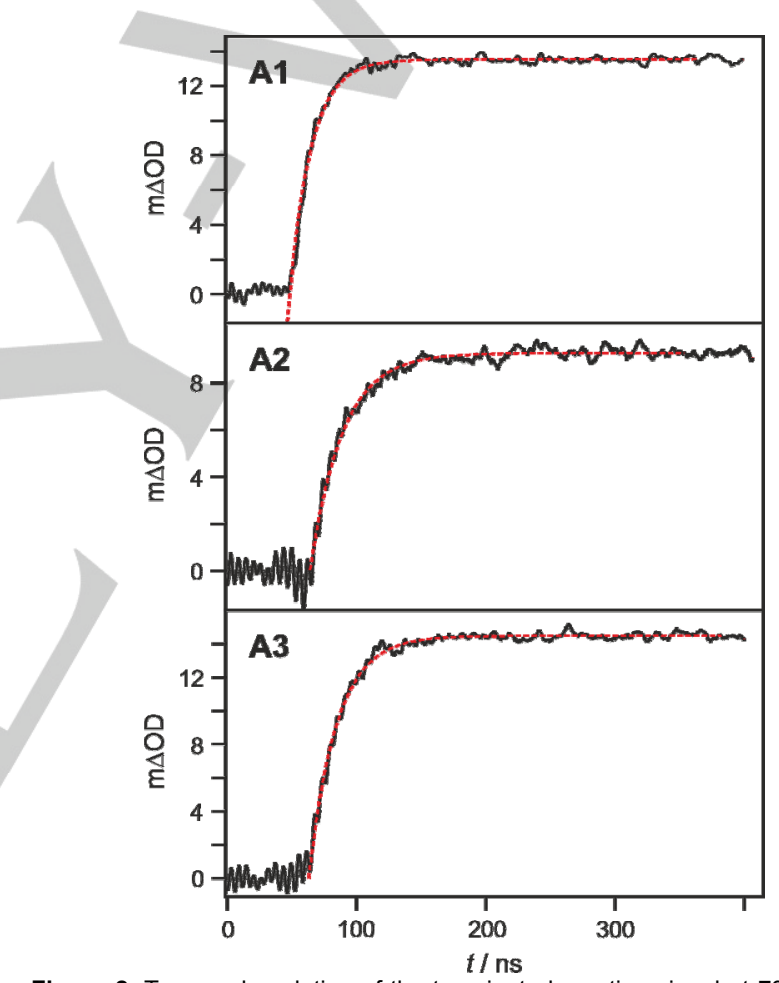

Figure 2. Temporal evolution of the transient absorption signal at $730 \mathrm{~nm}$ for compounds $\mathrm{A} 1$ - A3 following excitation at $532 \mathrm{~nm}$ with laser pulses of ca. 10 ns duration. The dyad and methylviologen concentrations were $15 \mu \mathrm{M}$ and 80 $\mathrm{mM}$, respectively, in all cases. The solvent was de-aerated $\mathrm{CH}_{3} \mathrm{CN}$ at $22{ }^{\circ} \mathrm{C}$. The dashed red lines are single-exponential fits.

Given these spectral characteristics, the rate constants for intramolecular electron transfer $\left(\mathrm{k}_{\mathrm{ET}}\right)$ from TAA to $\left[\mathrm{Ru}(\mathrm{bpy})_{3}\right]^{3+}$ in the 6 dyads can be determined by monitoring the temporal evolution of the transient absorption signal at $730 \mathrm{~nm}$. In the linear dyads L1 and L2, and in the control angled dyad C1, the risetime of the signal at $730 \mathrm{~nm}$ is instrumentally limited, and we can only estimate a lower limit of $10^{8} \mathrm{~s}^{-1}$ for $\mathrm{k}_{\mathrm{ET}}$ (SI, page S39). For the angled dyads $A 1, A 2$, and $A 3$, risetimes of $17 \pm 3,25 \pm 3$, and $21 \pm 3 \mathrm{~ns}$, respectively, are measured (Figure 2, Table 1). Thus, electron transfer is faster in the linear than in the angled isomers, but this is not particularly surprising because the former 
have a more extensively $\pi$-conjugated bridging system than the latter. The most significant observations are clearly the distance independence of $\mathrm{k}_{\mathrm{ET}}$ along the series of angled isomers (A1, A2, A3) and the faster electron transfer in the control compound $\mathrm{C} 1$ compared to A1, A2 and A3 (Table 1).

Table 1. Through-bond $\left(r_{\mathrm{tb}}\right)$ and through-space $\left(r_{\mathrm{ts}}\right)$ distances between the triarylamine $\mathrm{N}$-atom and the Ru-atom in the 6 dyads from Scheme 1, along with time $\left(\tau_{E T}\right)$ and rate constants $\left(k_{E T}\right)$ for electron transfer between TAA and photogenerated $\mathrm{Ru}(\mathrm{III})$. The through-space distances represent the lowest energy close-contact conformation of donor and acceptor calculated for geometry optimized structures using the MMFF level of theory (SI page S40).

\begin{tabular}{|c|c|c|c|c|}
\hline dyad & $r_{\mathrm{tb}} / \AA$ & $\mathrm{r}_{\mathrm{ts}} / \AA$ & $\tau_{\mathrm{ET}} / \mathrm{ns}$ & $\mathrm{k}_{\mathrm{ET}} / \mathrm{s}^{-1}$ \\
\hline L1 & 35.9 & & $<10$ & $>10^{8}$ \\
\hline L2 & 52.8 & & $<10$ & $>10^{8}$ \\
\hline A1 & 38.6 & 7.6 & $17 \pm 3$ & $(5.9 \pm 1.2) \cdot 10^{7}$ \\
\hline A2 & 55.4 & 8.9 & $25 \pm 3$ & $(4.0 \pm 0.5) \cdot 10^{7}$ \\
\hline $\mathrm{A} 3$ & 72.3 & 9.0 & $21 \pm 3$ & $(4.8 \pm 0.8) \cdot 10^{7}$ \\
\hline C1 & 38.6 & 19.5 & $<10$ & $>10^{8}$ \\
\hline
\end{tabular}

Prior studies on linear oligo-fluorene bridged donor-acceptor systems already reported very shallow distance dependences of through-bond electron transfer rates. ${ }^{[9 a, 9 b]}$ However, the distance dependence of $\mathrm{k}_{\mathrm{ET}}$, commonly captured by the so-called distance decay constant $(\beta)$, is not a bridge-specific property but rather it is governed by the entire combination of donor, bridge, and acceptor. $^{[17]}$ It is therefore difficult to make a general statement about the distance dependence of $\mathrm{k}_{\mathrm{ET}}$ for a given bridging structure. However, the hopping mechanism identified previously in some linear fluorene-bridged systems is likely to be operative in our dyads as well, $\left.{ }^{[9 a}, 9 b\right]$ because the oxidation potentials of the Ru photosensitizer and the oligo-fluorenes are very close to one another, ca. $1.3 \mathrm{~V}$ vs. SCE in both cases (SI page S33). Consequently, after photo-generation of $\left[\mathrm{Ru}(\mathrm{bpy})_{3}\right]^{3+}$, hole transfer to the molecular bridge is expected to be possible, and such a hopping mechanism is in line with the distance insensitivity of $\mathrm{k}_{\mathrm{ET}}$ observable in the angled series. ${ }^{\left[{ }^{[9}, 18\right]}$ However, for the angled dyads A1 - A3, through-space or through-solvent charge transfer pathways between TAA and $\left[\mathrm{Ru}(\mathrm{bpy})_{3}\right]^{3+}$ should also be considered, especially in view of the MMFF results discussed above.

The control compound $\mathrm{C} 1$ was specifically designed to probe the possibility of through-space electron transfer, because it cannot adopt conformations with short TAA-[Ru(bpy $\left.)_{3}\right]^{2+}$ contacts (Figure S9 on page S41) due to the different lengths of the donor and acceptor branches $(n=0, m=2$, Scheme 1). According to MMFF calculations the shortest possible throughspace $\mathrm{N}_{\text {TAA }}-\mathrm{Ru}$ distance in $\mathrm{C} 1$ is $19.5 \AA$. If direct through-space tunneling from the donor to the acceptor were to contribute significantly to $k_{E T}$ in any of the angled isomers $(A 1, A 2, A 3)$, one would expect the charge transfer rate to decrease for compound C1 (see SI page S42 for further details). The opposite phenomenon is instead observed $\left(k_{E T}>10^{8} \mathrm{~s}^{-1}\right.$ for $\mathrm{C} 1$, Table 1 and SI page S39), and thus it seems plausible to conclude that through-space tunneling plays only a minor role in A1, A2 and A3 if any at all. This is not overly surprising, as the flash-quench measurements were undertaken in acetonitrile, a highly polar solvent that can efficiently stabilize charges and therefore minimize the energy difference between open and closed conformers compared to what is obtained with the (crude) in vacuo MMFF calculations (see above and SI page S40-S41). For example, we recently reported electron transfer across a close-contact ion-pair which was significantly disrupted by even modestly polar solvents $\left(\mathrm{CH}_{2} \mathrm{Cl}_{2}\right.$, THF $){ }^{[19]}$ Given that the coulombic attraction in an ion-pair is significantly greater than for an ion-dipole system such as presented herein, it is unlikely that enough molecules exist in a close-contact conformation in acetonitrile. Electron tunneling through solvent is very inefficient compared to through-bond hopping. For example, the distance decay constant $(\beta)$ for tunneling through 2-methyl-THF is $1.6 \AA$ ${ }^{1,[20]}$ whilst for hopping processes the (phenomenological) $\beta$ values are usually below $0.1 \AA^{-1} .^{[18]}$ Thus, through-space and through-solvent tunneling seem to play a negligible role in our dyads, and through-bond pathways seem to be dominant.

The greater rate of electron transfer in $\mathrm{C} 1$ compared to $\mathrm{A} 1, \mathrm{~A} 2$ and $\mathrm{A} 3$ further gives implications for the mechanism of charge transfer. The linear series of complexes (L1, L2) clearly demonstrates that the hopping mechanism of hole transfer across fluorene bridges is extremely rapid. In the angled series however, the hole must tunnel through the spirobifluorene corner unit. This is likely to be the rate-limiting step of the hole transfer despite some spiroconjugation, ${ }^{[21]}$ and is corroborated by the more rapid rate of charge transfer in $\mathrm{C} 1$, which has the TAA electron donor located much closer to the spirobifluorene unit than any of the angled dyads $A 1, A 2$ and $A 3$, leading to stronger electronic coupling between TAA and spirofluorene. Consequently, the tunneling rate through the spirobifluorene corner is expected to increase in $\mathrm{C} 1$, as observed experimentally. However, hole tunneling between $\mathrm{Ru}(\mathrm{III})$ and its neighboring fluorene unit (rather than electron tunneling between TAA and the spirobifluorene corner) is likely to remain the initial key step of long-range charge transfer between $\mathrm{Ru}(\mathrm{III})$ and TAA (see SI pages S42-S43 for further details).

In summary, charge transfer in both the linear and angled dyads seems to be dominated by through-bond (hole) hopping mechanisms over distances of up to $70 \AA$. A lack of dependence of the electron transfer rate on the number of fluorene bridging units in the angled isomers is attributed to a rate-limiting hole tunneling step through the spirobifluorene corner. Despite the possible formation of conformers with relatively short donoracceptor contacts as a consequence of the relatively flexible long fluorene bridges, no evidence for direct through-space or through-solvent tunneling was observed, presumably due to the ability of acetonitrile to disrupt the ion-dipole attraction that would lead to such phenomena and the comparatively large $\beta$ values for tunneling through solvent. ${ }^{[2 \mathrm{~g}, 20]}$ Thus, the kinetics of charge transfer occurring over 40-70 $\AA$ can be governed by a single molecular corner unit. This key insight is relevant for the construction of multi-dimensional electron transfer systems or molecular grids ${ }^{[22]}$ in which individual molecular wires are connected by spirobifluorene or other corner-forming units. ${ }^{[23]}$ 


\section{Acknowledgements}

Financial support by the Swiss National Science Foundation through grant number 200021_146231/1 is acknowledged. C. B. L. acknowledges a Swiss Government Excellence Postdoctoral Scholarship for Foreign Scholars.

Keywords: electron transfer • time-resolved spectroscopy • donor-acceptor systems $\bullet$ molecular electronics $\bullet$ charge transfer

[1] a) L. T. Calcaterra, G. L. Closs, J. R. Miller, J. Am. Chem. Soc. 1983, $105,670-671$; b) M. M. Waskasi, G. Kodis, A. L. Moore, T. A. Moore, D. Gust, D. V. Matyushov, J. Am. Chem. Soc. 2016, 138, 9251-9257.

[2] a) F. Giacalone, J. L. Segura, N. Martín, D. M. Guldi, J. Am. Chem. Soc. 2004, 126, 5340-5341; b) E. A. Weiss, M. J. Ahrens, L. E. Sinks, A. V. Gusev, M. A. Ratner, M. R. Wasielewski, J. Am. Chem. Soc. 2004, 126 5577-5584; c) S. Barlow, C. Risko, S. J. Chung, N. M. Tucker, V. Coropceanu, S. C. Jones, Z. Levi, J. L. Brédas, S. R. Marder, J. Am. Chem. Soc. 2005, 127, 16900-16911; d) M. T. Indelli, C. Chiorboli, L. Flamigni, L. De Cola, F. Scandola, Inorg. Chem. 2007, 46, 5630-5641; e) F. Pevny, E. Di Piazza, L. Norel, M. Drescher, R. F. Winter, S. Rigaut Organometallics 2010, 29, 5912-5918; f) V. Lloveras, J. Vidal-Gancedo, T. M. Figueira-Duarte, J. F. Nierengarten, J. J. Novoa, F. Mota, N Ventosa, C. Rovira, J. Veciana, J. Am. Chem. Soc. 2011, 133, 5818 5833; g) J. R. Winkler, H. B. Gray, J. Am. Chem. Soc. 2014, 136, 29302939; h) M. Kuss-Petermann, O. S. Wenger, Angew. Chem. Int. Ed. 2016, 55, 815-819; i) Y. S. Luo, K. Barthelmes, M. Wächtler, A. Winter, U. S. Schubert, B. Dietzek, J. Phys. Chem. C 2017, 121, 9220-9229; j) T. Higashino, T. Yamada, M. Yamamoto, A. Furube, N. V. Tkachenko, T. Miura, Y. Kobori, R. Jono, K. Yamashita, H. Imahori, Angew. Chem. Int. Ed. 2016, 55, 629-633.

[3] a) M. B. Majewski, N. R. de Tacconi, F. M. MacDonnell, M. O. Wolf, Chem.-Eur. J. 2013, 19, 8331-8341; b) J. D. Megiatto, D. D. MendezHernandez, M. E. Tejeda-Ferrari, A. L. Teillout, M. J. Llansola-Portoles, G. Kodis, O. G. Poluektov, T. Rajh, V. Mujica, T. L. Groy, D. Gust, T. A. Moore, A. L. Moore, Nat. Chem. 2014, 6, 423-428; c) J. Melomedov, J. R. Ochsmann, M. Meister, F. Laquai, K. Heinze, Eur. J. Inorg. Chem. 2014, 2014, 1984-2001; d) G. N. Lim, C. O. Obondi, F. D'Souza, Angew. Chem. Int. Ed. 2016, 55, 11517-11521; e) K. Kitamoto, K. Sakai, Chem. Eur. J. 2016, 22, 12381-12390; f) K. Hu, A. D. Blair, E. J. Piechota, P. A Schauer, R. N. Sampaio, F. G. L. Parlane, G. J. Meyer, C. P Berlinguette, Nat. Chem. 2016, 8, 853-859; g) M. Yamamoto, J. Föhlinger, J. Petersson, L. Hammarström, H. Imahori, Angew. Chem. Int. Ed. 2017, 56, 3329-3333; h) A. Arrigo, F. Nastasi, G. La Ganga, F. Puntoriero, G. Zappala, A. Licciardello, M. Cavazzini, S. Quici, S. Campagna, Chem. Phys. Lett. 2017, 683, 96-104; i) S. Mendes Marinho, M.-H. Ha-Thi, V.-T. Pham, A. Quaranta, T. Pino, C. Lefumeux, T. Chamaillé, W. Leibl, A. Aukauloo, Angew. Chem. Int. Ed. 2017, 56, 15936-15940.

[4] a) P. F. H. Schwab, M. D. Levin, J. Michl, Chem. Rev. 1999, 99, 18631933; b) N. Aratani, A. Osuka, Y. H. Kim, D. H. Jeong, D. Kim, Angew. Chem. Int. Ed. 2000, 39, 1458-1462; c) M. Mayor, H. B. Weber, J. Reichert, M. Elbing, C. von Hänisch, D. Beckmann, M. Fischer, Angew. Chem. Int. Ed. 2003, 42, 5834-5838; d) A. C. Benniston, A. Harriman Chem. Soc. Rev. 2006, 35, 169-179; e) K. Venkatesan, O. Blacque, H. Berke, Dalton Trans. 2007, 1091-1100; f) M. J. Frampton, H. L. Anderson, Angew. Chem. Int. Ed. 2007, 46, 1028-1064; g) P. P. Lainé, S. Campagna, F. Loiseau, Coord. Chem. Rev. 2008, 252, 2552-2571 h) H. A. Meylemans, J. T. Hewitt, M. Abdelhaq, P. J. Vallett, N. H. Damrauer, J. Am. Chem. Soc. 2010, 132, 11464-11466; i) D. C O'Hanlon, B. W. Cohen, D. B. Moravec, R. F. Dallinger, M. D. Hopkins, J. Am. Chem. Soc. 2014, 136, 3127-3136; j) N. Gorczak, N. Renaud, S Tarkuc, A. J. Houtepen, R. Eelkema, L. D. A. Siebbeles, F. C. Grozema, Chem. Sci. 2015, 6, 4196-4206
[5] K. G. Alley, G. Poneti, P. S. D. Robinson, A. Nafady, B. Moubaraki, J. B. Aitken, S. C. Drew, C. Ritchie, B. F. Abrahams, R. K. Hocking, K. S Murray, A. M. Bond, H. H. Harris, L. Sorace, C. Boskovic, J. Am. Chem. Soc. 2013, 135, 8304-8323.

[6] a) V. Balzani, Electron transfer in chemistry, Vol. 3, VCH Wiley, Weinheim, 2001; b) P. J. Low, Dalton Trans. 2005, 2821-2824.

[7] Y. Hirao, M. Urabe, A. Ito, K. Tanaka, Angew. Chem. Int. Ed. 2007, 46, 3300-3303.

[8] M. Delor, S. A. Archer, T. Keane, A. Meijer, I. V. Sazanovich, G. M Greetham, M. Towrie, J. A. Weinstein, Nat. Chem. 2017, 9, 1099-1104.

[9] a) R. H. Goldsmith, L. E. Sinks, R. F. Kelley, L. J. Betzen, W. H. Liu, E. A. Weiss, M. A. Ratner, M. R. Wasielewski, Proc. Natl. Acad. Sci. U. S. A. 2005, 102, 3540-3545; b) C. Atienza-Castellanos, M. Wielopolski, D. M. Guldi, C. van der Pol, M. R. Bryce, S. Filippone, N. Martín, Chem. Commun. 2007, 5164-5166; c) C. S. Wang, M. R. Bryce, J. Gigon, G. J. Ashwell, I. Grace, C. J. Lambert, J. Org. Chem. 2008, 73, 4810-4818; d) V. A. Montes, G. V. Zyryanov, E. Danilov, N. Agarwal, M. A. Palacios, P. Anzenbacher, J. Am. Chem. Soc. 2009, 131, 1787-1795; e) M. P. Eng, B. Albinsson, Chem. Phys. 2009, 357, 132-139; f) J. Vura-Weis, S. H. Abdelwahed, R. Shukla, R. Rathore, M. A. Ratner, M. R. Wasielewski, Science 2010, 328, 1547-1550; g) M. Wielopolski, J. Santos, B. M. Illescas, A. Ortiz, B. Insuasty, T. Bauer, T. Clark, D. M. Guldi, N. Martin, Energy Environ. Sci. 2011, 4, 765-771; h) Y. Shibano, H. Imahori, P. Sreearunothai, A. R. Cook, J. R. Miller, J. Phys. Chem. Lett. 2010, 1, 1492-1496; i) F. Malvolti, C. Rouxel, O. Mongin, P. Hapiot, L. Toupet, M. Blanchard-Desce, F. Paul, Dalton Trans. 2011, 40, 66166618; j) R. S. Klausen, J. R. Widawsky, T. A. Su, H. Li, Q. Chen, M. L. Steigerwald, L. Venkataraman, C. Nuckolls, Chem. Sci. 2014, 5, 15611564 ; k) S. H. Choi, C. Risko, M. C. R. Delgado, B. Kim, J. L. Brédas, C. D. Frisbie, J. Am. Chem. Soc. 2010, 132, 4358-4368; I) C. Sagan, Y. Jiang, F. Caban, J. Snaider, R. Amell, S. Wei, G. M. Florio, J. Phys. Chem. C 2017, 121, 24945-24953.

[10] a) Y. L. Liao, W. Y. Hung, T. H. Hou, C. Y. Lin, K. T. Wong, Chem Mater. 2007, 19, 6350-6357; b) T. P. I. Saragi, T. Spehr, A. Siebert, T Fuhrmann-Lieker, J. Salbeck, Chem. Rev. 2007, 107, 1011-1065; c) C Stobe, R. Seto, A. Schneider, A. Lützen, Eur. J. Org. Chem. 2014, 6513-6518.

[11] a) M. M. Sartin, C. F. Shu, A. J. Bard, J. Am. Chem. Soc. 2008, 130, 5354-5360; b) Y. Y. Chien, K. T. Wong, P. T. Chou, Y. M. Cheng Chem. Commun. 2002, 2874-2875; c) K. T. Wong, S. Y. Ku, Y. M. Cheng, X. Y. Lin, Y. Y. Hung, S. C. Pu, P. T. Chou, G. H. Lee, S. M. Peng, J. Org. Chem. 2006, 71, 456-465; d) B. Ventura, A. Barbieri, A. Degli Esposti, J. B. Seneclauze, R. Ziessel, Inorg. Chem. 2012, 51, 2832-2840.

[12] T. A. Halgren, R. B. Nachbar, J. Comput. Chem. 1996, 17, 587-615.

[13] a) K. Kumar, Z. Lin, D. H. Waldeck, M. B. Zimmt, J. Am. Chem. Soc. 1996, 118, 243-244; b) N. R. Lokan, M. N. Paddon-Row, M. Koeberg, J. W. Verhoeven, J. Am. Chem. Soc. 2000, 122, 5075-5081; c) B. M. Graff, D. N. Lamont, M. F. L. Parker, B. P. Bloom, C. E. Schafmeister, D. H. Waldeck, J. Phys. Chem. A 2016, 120, 6004-6013; d) M. Uebe, T. Kazama, R. Kurata, D. Sakamaki, A. Ito, Angew. Chem. Int. Ed. 2017 56, 15712-15717.

[14] a) M. J. Bjerrum, D. R. Casimiro, I.-J. Chang, A. J. Di Bilio, H. B. Gray, M. G. Hill, R. Langen, G. A. Mines, L. K. Skov, J. R. Winkler, D. S Wuttke, J. Bioenerg. Biomembr. 1995, 27, 295-302; b) M. E. Walther, O. S. Wenger, ChemPhysChem 2009, 10, 1203-1206.

[15] B. Geiss, C. Lambert, Chem. Commun. 2009, 1670-1672.

[16] a) M. L. A. Abrahamsson, H. B. Baudin, A. Tran, C. Philouze, K. E. Berg, M. K. Raymond-Johansson, L. C. Sun, B. Åkermark, S. Styring, L. Hammarström, Inorg. Chem. 2002, 41, 1534-1544; b) P. S. Braterman, J. I. Song, J. Org. Chem. 1991, 56, 4678-4682.

[17] a) F. D. Lewis, J. Q. Liu, W. Weigel, W. Rettig, I. V. Kurnikov, D. N. Beratan, Proc. Natl. Acad. Sci. U. S. A. 2002, 99, 12536-12541; b) M. P. Eng, B. Albinsson, Angew. Chem. Int. Ed. 2006, 45, 5626-5629; c) B. Albinsson, M. P. Eng, K. Pettersson, M. U. Winters, Phys. Chem. Chem. Phys. 2007, 9, 5847-5864; d) M. Natali, S. Campagna, F. Scandola, 
Chem. Soc. Rev. 2014, 43, 4005-4018; e) C. Herrmann, J. Elmisz, Chem. Commun. 2013, 49, 10456-10458.

[18] M. Cordes, B. Giese, Chem. Soc. Rev. 2009, 38, 892-901.

[19] C. B. Larsen, O. S. Wenger, Angew. Chem. Int. Ed. 2018, 57, 841-845.

[20] O. S. Wenger, B. S. Leigh, R. M. Villahermosa, H. B. Gray, J. R. Winkler, Science 2005, 307, 99-102.

[21] H. E. Simmons, T. Fukunaga, J. Am. Chem. Soc. 1967, 89, 5208-5215.
[22] D. M. Bassani, J. M. Lehn, S. Serroni, F. Puntoriero, S. Campagna, Chem. Eur. J. 2003, 9, 5936-5946.

[23] A. Mishra, C. Q. Ma, P. Bäuerle, Chem. Rev. 2009, 109, 1141-1276. 


\section{Entry for the Table of Contents}

\section{COMMUNICATION}

The kinetics of hole hopping over 40$70 \AA$ are governed by a ratedetermining tunneling step across a spirobifluorene corner unit. This finding is relevant for the construction of multi-dimensional electron transfer systems or grids in which individual molecular wires are interlinked at $90^{\circ}$ angles.
Hauke C. Schmidt, Christopher B. Larsen, Oliver S. Wenger*

Page No. - Page No.
VS.

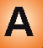

Electron Transfer around a Molecular Corner 